\title{
I.UMIBUNG
}

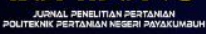

\section{DISTRIBUSI PARASITOID Ooencyrtus malayensis DI PERTANAMAN PADI SUMATERA BARAT SEBAGAI KANDIDAT PENGENDALI HAYATI WALANG SANGIT (Leptocorisa oratorius F.)}

\author{
Fri Maulina ${ }^{1}$ dan Muflihayati ${ }^{1}$ \\ ${ }^{1}$ Politeknik Pertanian Negeri Payakumbuh \\ Korespondensi: maulinafri@yahoo.co.id
}

$\begin{array}{ll}\text { Diterima } & : 06 \text { Februari } 2020 \\ \text { Disetujui } & : \text { 25 Agustus 2020 } \\ \text { Diterbitkan } & : \text { 31 Agustus 2020 }\end{array}$

\begin{abstract}
ABSTRAK
Pemberdayaan musuh alami hama seperti parasitoid Ooencyrtus malayensis sebagai pengendali hayati walang sangit dapat meminimalisir penggunaan insektisida kimia dan memiliki nilai positif yaitu mengendalikan hama pada stadia awal perkembangannya. Tujuan penelitian adalah: menentukan distribusi populasi parasitoid pada topografi Sumatera Barat yang berbeda, dan menentukan tingkat parasitisasi, dominansi dan mortalitas parasitoid tersebut. Pengambilan sampel telur walang sangit terparasit di lokasi padi sawah dengan metode stratifield sampling pada tiga ketinggian tempat yaitu: Sungai Sapih Kota Padang, Rendah (20 m dpl ), Tanjung Pati Kabupaten Limapuluh Kota, Sedang (500 m dpl), dan Kubang Putih Kabupaten Agam, Tinggi $(975 \mathrm{~m} \mathrm{dpl}$ ). Sampel telur diamati di laboratorium untuk mengetahui telur yang terparasit oleh $O$. malayensis dan selanjutnya data dianalisis. Hasil penelitian membuktikan bahwa distribusi parasitoid O. malayensis lebih dominan pada lokasi lokasi dataran rendah selanjutnya dataran sedang sedangkan pada dataran tinggi tidak ditemukan. Tingkat parasitisasi pada dataran rendah dan tinggi adalah $13 \%$ dan $6 \%$. Sedangkan nilai mortalitas parasitoid $O$. malayensis pada dataran rendah dan tinggi adalah 17 $\%$ dan $33 \%$. Dari penemuan ini disimpulkan bahwa parasitoid O. malayensis menyukai lokasi dengan ketinggian rendah dri permukaan laut dan dapat memparasitisasi telur walang sangit dengan tingkat serangan yang cukup tinggi.
\end{abstract}

Kata Kunci: Ooencyrtus malayensis, distribusi, parasitisasi, dominansi, mortalitas

\section{ABSTRACT}

Empowerment of natural enemies of pests such as the parasitoid Ooencyrtus malayensis as a biological controller can reduce the use of chemical insecticides and have a positive value that is controlling pests in the early stages of development. The research objectives are determine the distribution of parasitoid populations in different topography of West Sumatra, and determine the level of parasitization and mortality of these parasitoids. Sampling of parasitizated rice bug eggs in the location of wetland with stratifield sampling method at three altitudes namely: Sungai Sapih, Padang City, Low land (20 $\mathrm{m}$ asl), Tanjung Pati, Limapuluh Kota Regency, Middle land (500 m asl), and Kubang Putih, Agam Regency, Heigh land (975 $\mathrm{m} \mathrm{asl}$ ). Egg samples were observed in the laboratory to find eggs that were parasitized by $O$. malayensis and then the data were analyzed. The results prove that the distribution of the parasitoid $O$. malayensis is more dominant at the location of the lowland 


\section{I.UMIBUNG}

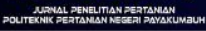

and midleland, while highland was not found. The level of parasitization in the lowlands and middlelands are $13 \%$ and $6 \%$. While the mortality of parasitoid O. malayensis in the lowlands and middlelands are 17\% and 33\%. From this discovery it was concluded that the parasitoid $O$. malayensis favored locations with low altitude from sea level and could parasitize stinking eggs with a fairly high attack rate.

\section{Keywords: Ooencyrtus malayensis, distribution, parasitization, dominance, mortality}

\section{PENDAHULUAN}

Penggunaan agens hayati merupakan cara pengendalian yang tidak memiliki dampak negatif terhadap lingkungan. Salah satu jenis agens hayati adalah parasitoid yang merupakan musuh alami yang penting dalam konsep pengendalian hayati. Parasitoid dapat melumpuhkan inangnya secara perlahan (Maulina et al, 2018) dan memiliki keunggulan karena mengendalikan pada stadia awal perkembangan hama (Hidrayani et al, 2013). Ooencyrtus merupakan parasitoid telur polipag (Tunca et al, 2016) yang dapat memparasiti telur serangga hama pertanian dan kehutanan, antara lain walang sangit (Winasa et al, 1997; Jamili dan Anggraeni, 2012; Maulina et al , 2018), dan kepik buah lada (Alwi dan Soetopo, 2000). Ooencyrtus Ashmead termasuk famili Encyrtidae dari ordo Hymenoptera dan dilaporkan memiliki spesies yang cukup banyak, yaitu mencapai 200 spesies. Penamaan spesies Ooencyrtus berdasarkan bentuk morfologi antena yang dimilikinya (Zhang et al, 2005). Daerah persebarannya meliputi Amerika Serikat, Eropa, Afrika Utara, Jepang, Asia Tenggara, dan Indo-Pasifik.

Spesies Ooencyrtus malayensis dan Hadronotus leptocorisae dilaporkan Maulina et al (2016) memparasiti telur walang sangit yang berada di padi sawah Tanah Datar, Sumatera Barat. Parasitoid O. malayensis juga dilaporkan memarasiti telur Nezara viridula Linneaus (Hemiptera: Pentatomidae) pada polong kedelai dan Dasynus piperis China (Hemiptera: Coreidae) pada buah lada. Parasitoid O. malayensis yang berasal (keluar) dari telur kepik buah lada bisa berkembang pada telur kepik polong kedelai. (Alwi dan Soetopo, 2000). Hal ini menggambarkan bahwa parasitoid ini bisa dikembangkan pada inang alternatif dan berpotensi dikembangkan dilaboratorium sebagai agens pengendali hayati serangga hama.

Penemuan awal parasitoid O. malayensis pada lokasi Sumatera Barat menimbulkan pemikiran bahwa pada lokasi lain di Sumatera Barat akan ditemukan parasitoid tersebut. Kajian distribusi parasitoid $O$. malayensis perlu dilakukan agar diketahui daya adaptasinya di berbagai topografi penanaman padi sawah. Hal ini akan memudahkan dalam usaha 


\section{I.UMIBUNG}

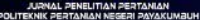

perbanyakannya di laboratorium sehingga dapat digunakan sebagai agens pengendali hayati hama walang sangit di lapangan. Kebanyakan kegagalan penggunaan agens hayati parasitoid yang berkaitan dengan kurangnya kesesuaian hidup dan pemahaman tentang biologi dari parasitoid (Ilacer et al, 2006; Nelly et al, 2011; Maulina et al, 2018). Oleh karena itu informasi distribusi dan adaptasi parasitoid O. malayensis di topografi Sumatera Barat perlu dilakukan.

Tujuan penelitian adalah untuk : 1) Menentukan distribusi populasi parasitoid $O$. malayensis pada 3 topografi Sumatera Barat, 2) Menentukan tingkat parasitisasi dan mortalitas parasitoid $O$. malayensis pada topografi berbeda tersebut.

\section{METODOLOGI}

\section{Waktu dan Tempat}

Pengambilan sampel telur walang sangit dilakukan pada tiga lokasi yang mewakili topografi pertanaman padi di Sumatera Barat. Kajian biologi dan distribusi populasi parasitoid Ooencyrtus malayensis dari masing-masing lokasi sampel dilakukan di laboratorium tanaman Pangan Politeknik Pertanian Negeri Payakumbuh. Kegiatan dilakukan sejak Mei hingga Agustus 2019.

\section{Bahan dan Alat}

Bahan yang digunakan dalam penelitian ini antara lain kertas label, kain kassa, kapur ajaib, madu 10\%, alkohol 96\%, tabung appendorf, dan tissu. Alat yang digunakan adalah pinset ujung runcing, termohygrometer, hand sprayer, kuas kecil, kuas besar, jarum berkepala, jarum serangga, penggaris, aspirator, tabung reaksi 7 dan10 cm, kotak plastik berjendela kasa $(22 \mathrm{~cm} \times 15 \mathrm{~cm}$ x $7 \mathrm{~cm})$, ruang penyimpanan, gunting, bak kecambah (pesemaian), ember, jaring serangga berdiameter 10 dan $30 \mathrm{~cm}$, meteran, rak tabung reaksi besi, loupe, mikroskop binokuler Carton HZ, camera digital Olympus SZ-14, laptop, dan alat tulis (pena, pensil, kertas HVS).

\section{Metode Pelaksanaan}

\section{Pengambilan sampel di lapangan}

Penelitian ini merupakan penelitian survai untuk pengambilan sampel pada pertanaman padi di Sumatera Barat dan dilanjutkan dengan pengujian secara deskriptif di 


\section{I.UMIBUNG}

laboratorium. Lokasi sampel ditentukan dengan menggunakan metode stratifield sampling, yaitu tiga lokasi ketinggian tempat berbeda :

A. Dataran Rendah yaitu Sungai Sapih Kota Padang (20 m dpl)

B. Dataran Sedang Tanjung Pati Kabupaten Limapuluh Kota (500 m dpl),

C. Dataran Tinggi Kubang Putih Kabupaten Agam (975 m dpl).

Kriteria luas hamparan sawah yang digunakan sebagai lokasi penelitian adalah kondisi tanaman padi pada stadia mulai berbunga hingga stadia matang susu. Pengambilan sampel dilakukan secara transek sepanjang $1 \mathrm{~km}$, kemudian telur walang sangit yang ditemukan di kanan dan kiri akan diambil. Bila jarak belum terpenuhi akan berbelok hingga mencapai $1 \mathrm{~km}$. Sampel yang terkumpul selanjutnya dibawa ke laboratorium.

\section{Pengamatan di laboratorium}

\section{Morfologi dan Ukuran Imago Parasitoid O. malayensis}

Sepuluh imago parasitoid difoto dengan menggunakan camera digital Olympus SZ 14. Pengukuran dilakukan dengan menampilkan foto, kemudian titik terjauh dari objek ditandai menggunakan mouse (misalnya untuk objek pangkal sayap ditandai pada pangkal sayap dan ujung sayap terjauh).

\section{Lama hidup imago parasitoid}

Pengamatan dilakukan setiap hari dimulai saat imago parasitoid muncul hingga mati. Sepuluh sampel imago yang masih hidup ditandai sehingga diperoleh lama hidup masingmasingnya.

\section{Jumlah Telur Terparasit}

Pengamatan dilakukan terhadap sampel kelompok telur yang telah ditempatkan dalam tabung reaksi. Telur yang menetas menjadi nimfa walang sangit adalah telur yang tidak terparasit, sedangkan yang menetas menjadi imago selain walang sangit adalah yang terparasit. Penghitungan dilakukan hanya untuk parasitoid O. malayensis. Telur yang tidak menetas dalam waktu 25 hari akan dibedah di bawah mikroskop binokuler untuk menentukan terparasit atau tidak.

\section{Analisis data}

\section{Tingkat Parasitisasi}

Pada sampel telur yang tidak menetas dilakukan pembedahan, yakni 25 hari setelah dilakukan pengamatan. Pembedahan dilakukan di bawah mikroskop stereo binokuler untuk mengetahui telur berisi imago walang sangit, parasitoid, atau bukan keduanya. Tingkat 


\section{I.UMIRUNG}

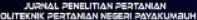

parasitisasi parasitoid telur walang sangit yang keluar dari telur dihitung menggunakan rumus:

$$
\mathrm{P}=\frac{A}{B} \times 100 \%
$$

Keterangan: $\mathrm{P}=$ Persentase parasitisasi parasitoid
$\mathrm{A}=$ Jumlah telur terparasit (keluar parasitoid, tidak menetas, abnormal)
$\mathrm{B}=$ Jumlah semua sampel telur yang diamati

\section{Mortalitas Parasitoid}

Mortalitas parasitoid telur walang sangit dihitung pada 10 ekor parasitoid $O$. malayensis yang ditemukan. Rumus yang digunakan adalah sebagai berikut:

$$
\mathrm{M}=\frac{A}{B} \times 100 \%
$$

Keterangan: $\mathrm{M}=$ Mortalitas parasitoid

$$
\begin{aligned}
& \mathrm{A}=\text { Jumlah parasitoid yang mati } \\
& \mathrm{B}=\text { Jumlah semua parasitoid }
\end{aligned}
$$

\section{HASIL DAN PEMBAHASAN}

\section{Morfologi, Ukuran dan Lama Hidup parasitoid Ooencystus malayensis}

Sampel telur walang sangit terparasit dikumpulkan dari tiga lokasi yaitu mulai dari dataran rendah, sedang hingga tinggi. Pengamatan terhadap sampel telur yang terparasit di laboratorium menemukan dua jenis parasitoid yaitu Ooencyrtus malayensis dan Hadronotus leptocorisae. Secara morfologi parasitoid O. malayensis memiliki ukuran yang lebih kecil dari pada parasitoid $H$. leptocorisae, namun dengan mata telanjang sulit membedakannya. Penggunaan mikroskop binokuler dapat membedakan kedua jenis parasitoid secara morfologi.

Bagian tubuh dari parasitoid O. malayensis tidak semuanya hitam. Pada caput dan thorak berwarna hitam, sedangkan pada pangkal abdomen berwarna kuning kemudian berikutnya berwarna hitam. Kaki dan antena berwarna kuning. Parasitoid O. malayensis memiliki bentuk sayap dengan venasi (pembuluh) yang sederhana yang menjadi ciri Ordo Hymenoptera. Parasitoid ini tergolong pada subordo Apocrita dengan superfamili Chalcidoidea dan famili Encyrtidae. Bagian tubuh dari parasitoid O. malayensis tidak semuanya hitam. Pada caput dan thorak berwarna hitam, sedangkan pada pangkal abdomen 


\section{I.UMIRUNC}

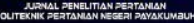

berwarna kuning kemudian berikutnya berwarna hitam. Kaki dan antena berwarna kuning. Antena betina dan jantan juga memiliki bentuk yang berbeda. Ujung antena betina menggada dan memiliki tiga segmen, sedangkan pada antena jantan terlihat sama besar. Ciri spesifik famili Encyrtidae yang membedakannya dengan Scelionidae antara lain adalah adanya bulu pada bagian pangkal abdomen di kanan dan kiri yang terlihat secara dorsal (Gambar 1). Menurut CSIRO (1991) famili Encyrtidae memiliki sayap depan dengan pembuluh stigmal dan marginal (submarginal, postmarginal). Encyrtidae memiliki maksimal 11 segmen. Ukuran tubuh secara rata-rata adalah $\pm 1 \mathrm{~mm}$. Menurut CSIRO (1991) famili Encyrtidae kebanyakan endoparasitoid pada hemiptera. Hal ini sesuai dengan laporan Zhang et al. (2005) dan Ebrahimi et al. (2014) bahwa antena betina Ooencyrtus memiliki ujung flagellum yang membesar, dan biasanya bagian tersebut terdiri dari 3 segmen, sedangkan pada jantan flagellum terlihat relatif sama. Menurut Guelet dan Huber (1993) bagian flagellomere yang membesar tersebut dinamakan club.

\begin{tabular}{|c|c|}
\hline Imago & $\begin{array}{c}\text { Bulu pada pangkal abdomen di } \\
\text { bagian kanan dan kiri }\end{array}$ \\
\hline & \\
\hline Sayap depan & Sayap belakang \\
\hline Antena Jantan & Antena Betina \\
\hline & \\
\hline
\end{tabular}

Gambar 1. Morfologi parasitoid O. malayensis (Hymenoptera : Encyrtidae) 


\section{I.UMIBUNC}

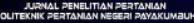

Pengamatan ukuran tubuh parasitoid O. malayensis yang ditemukan pada lokasi dataran rendah (Sungai Sapih) lebih kecil dibanding dataran sedang (Tanjung Pati) yaitu 0,7 $\pm 0,2$ dan 1,0 $\pm 0,1 \mathrm{~mm}$ masing-masingnya (Tabel 1). Pada lokasi pengamatan dataran tinggi (Kubang Putih) tidak ditemukan parasitoid O. malayensis. Ukuran tubuh ini bervariasi tergantung jumlah individu di dalam satu telur. Parasitoid O. malayensis merupakan gregarius sehingga pada satu telur ditemukan lebih dari satu individu.

Tabel 1. Ukuran dan lama hidup parasitoid Ooencyrtus. malayensis pada telur walang sangit (Leptocorisa oratorius)

$\begin{array}{cccc}\text { Lokasi } & \text { Ketinggian tempat } & \text { Ukuran tubuh } & \text { Rerata } \\ \text { Sampel } & (\mathrm{m} \mathrm{dpl}) & (\mathrm{mm}) & \text { Lama hidup } \\ & & & \text { (hari) }\end{array}$

\begin{tabular}{|c|c|c|c|}
\hline $\begin{array}{l}\text { Sungai Sapih } \\
\text { Kec. Kuranji } \\
\text { Padang }\end{array}$ & $\begin{array}{c}20 \\
\text { Dataran rendah }\end{array}$ & $0,7 \pm 0,2$ & 12,5 \\
\hline $\begin{array}{c}\text { Tanjung Pati } \\
\text { Kec. Harau } \\
\text { Limapuluh Kota }\end{array}$ & $\begin{array}{c}500 \\
\text { Dataran sedang }\end{array}$ & $1,0 \pm 0,1$ & 13,3 \\
\hline $\begin{array}{l}\text { Kubang Putih } \\
\text { Kec. Sei Puar } \\
\text { Agam }\end{array}$ & $\begin{array}{c}975 \\
\text { Dataran tinggi }\end{array}$ & - & - \\
\hline
\end{tabular}

Keterangan : $\mathrm{dpl}=$ di atas permukaan laut, $\mathrm{m}=$ meter, $\mathrm{O} \mathrm{m}=$ Ooencyrtus

malayensis, *sampel masih ada yang diamati

\section{Parasitisasi dan Mortalitas}

Tingkat parasitisasi parasitoid $O$. malayensis pada ketiga lokasi yang di teliti menunjukkan bahwa semakin dekat dengan laut maka semakin tinggi tingkat parasitisasinya. Keberadaan parasitoid dan parasitisasinya diduga terkait dengan lebih sesuainya kondisi suhu bagi perkembangan parasitoid maupun serangga inangnya. Ketinggian tempat berhubungan dengan suhu sebagaimana pendapat Syarkawi et al, (2015) bahwa setiap kenaikan lokasi tempat sejauh $100 \mathrm{~m}$, maka suhu akan turun $0,5-1^{\circ} \mathrm{C}$. Pada suhu toleransi, kenaikan suhu akan memacu metabolisme tubuh sebanyak 2 kali. Selain itu tingkat parasitisasi juga dipengaruhi oleh keberadaan inang, karena tanpa inang parasitoid tidak dapat menempatkan inangnya. 


\section{I.UMIAUNC}

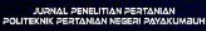

Tabel 2. Parasitasi dan mortalitas parasitoid Ooencyrtus. malayensis pada telur walang sangit (Leptocorisa oratorius)

\begin{tabular}{|c|c|c|c|c|}
\hline $\begin{array}{l}\text { Lokasi } \\
\text { Sampel }\end{array}$ & $\begin{array}{l}\text { Ketinggian tempat } \\
\text { (m dpl) }\end{array}$ & $\begin{array}{c}\text { Jumlah } \\
\text { sampel telur } \\
\text { (butir) }\end{array}$ & $\begin{array}{c}\text { Parasitisasi } \\
(\%)\end{array}$ & $\begin{array}{c}\text { Mortalitas } \\
(\%)\end{array}$ \\
\hline $\begin{array}{l}\text { Sungai Sapih } \\
\text { Kec. Kuranji } \\
\text { Padang }\end{array}$ & $\begin{array}{c}20 \\
\text { Dataran rendah }\end{array}$ & 228 & 13 & 17 \\
\hline $\begin{array}{c}\text { Tanjung Pati } \\
\text { Kec. Harau } \\
\text { Limapuluh Kota }\end{array}$ & $\begin{array}{c}500 \\
\text { Dataran sedang }\end{array}$ & 322 & 6 & 33 \\
\hline $\begin{array}{l}\text { Kubang Putih } \\
\text { Kec. Sei Puar } \\
\text { Agam }\end{array}$ & $\begin{array}{c}975 \\
\text { Dataran tinggi }\end{array}$ & 5 & 0 & 0 \\
\hline
\end{tabular}

Keterangan : $\mathrm{dpl}=$ di atas permukaan laut, $\mathrm{m}=$ meter, $\mathrm{O} \mathrm{m}=$ Ooencyrtus malayensis, *sampel masih ada yang diamati

\section{KESIMPULAN}

1. Distribusi parasitoid O. malayensis di Sumatera Barat ditemukan pada dataran rendah dan sedang, sedangkan pada dataran tinggi tidak ditemukan.

2. Tingkat parasitisasi parasitoid $O$. malayensis pada dataran rendah dan sedang adalah $13 \%$ dan $6 \%$, sedangkan mortalitasnya $15 \%$ banding $5 \%$.

\section{REFERENSI}

Alwi, A., dan D. Soetopo. 2000. Biologi Ooencyrtus malayensis Ferr. Parasitoid Telur Dasynus piperis China pada Inang Alternatif Nezara viridula L. J. Penelitian Tanaman Industri 6(3): 82-88

Commenwealth Scientific and Industrial Research Organisation (CSIRO). 1991. The insect of Australia Vol.II. Melbourne University Press, Carlton, Victoria. 1137 p.

Ebrahimi, E., G.R.T. Korghond., K. Mianbandi., H. Mahmoodi., K. Muhammadipour., dan J. Noyes. 2014. Ooencyutus ferdowssii sp. n. (Hymenoptera: Encyrtidae) an egg parasitoid of Osphranteria coerulescens (Coleoptera : Cerambycidae) in Iran. Zoology in Middle East.

Guelet, H., dan J.T. Huber. 1993. Hymenoptera of world: An identification guide to families. Canada Communication Group Publishing. Ottawa . Canada. 668 hal. 


\section{I.UMIBUNG}

Hidrayani., R. Rusli dan Y.S. Lubis. 2013. Keanekaragaman Spesies Parasitoid Telur Hama Lepidoptera dan Parasitasinya Pada Beberapa Tanaman di Kabupaten Solok Sumatera Barat. J. Natur Indonesia 15(1): 9-14.

Ilacer, E., A. Urbaneja., A. Garrido., dan J.A. Jacas. 2006. Temperature Requirements May Explain Why The Introduced Parasitoid Quadrastichus Citrella Failed to Control Phyllocnistis citrella in Spain. J. Biocontrol 51(4): 439-452.

Jamili, A., dan T. Anggraeni. 2012. Sex ratio parasitoid telur Hadronotus leptocorisae (Hymenoptera: Scelionidae) pada telur Leptocorisa acuta (Hemiptera: Alydidae) muda dan dewasa. J Agroteksos 22(1): 50-57.

Maulina F., N. Nelly., Hidrayani., dan H. Hamid. 2016. Keanekaragaman Spesies dan Parasitisasi parasitoid Telur Walang Sangit (Leptocorisa oratorius Fabricius) di Kabupaten Tanah Datar. Pross. Seminar Nasional Masyarakat Biodiversitas Indonesia 2( 1): 109-112

Maulina F., N. Nelly., Hidrayani., dan H. Hamid. 2018. Parasitizations Levels and Temperature Tolerance of Rice Bug (Leptocorisa oratorius Fabricius) Egg Parasitoids: Mass Rearing for Biological Control. Ijaseit 8(3): 714-719.

Nelly, N., T. Habazar., R. Syahni., dan D. Buchori. 2011. Pengaruh Suhu Terhadap Perkembangan Pradewasa Parasitoid Eriborus argenteopilosus Cameron (Hymenoptera: Ichneumonidae). J. Natur Indonesia. 13(03): 250-255.

Romani, R., N. Isidoro., dan F. Bin. 2010. Antennal Structures Used in Communication by Egg Parasitoid. Dalam Consoli F.L., J.R.P. Parra., R.A. Zucchi, editor. Progress in Biological Control: Egg Parasitoids in Agroecosystem with Emphases on Trichogramma. Heidenberg: Springer Science. 57-91.

Syarkawi., Husni., dan M. Sayuthi. 2015. Pengaruh Tinggi Tempat Terhadap Tingkat Serangan Hama Penggerek Buah Kakao (Conopomorpha cramerella Snellen) di Kabupaten Pidie. J. Floratek (10(2): 52-60.

Tunca. H., M. Buradino., E-A. Colombel., Dan E. Tabone. 2016. Tendency and consequences of superparasitism for the parasitoid Ooencyrtus pityocampae (Hymenoptera: Encyrtidae) in parasitizing a new laboratory host, Philosamia ricini (Lepidoptera: Saturniidae). Eur. J. Entomol. 113: 51-59.

Zhan, Y-Z., W. Li ., and D-W. Huang. 2005. A Taxonomic Study of Chinese Species of Ooencyrtus (Insecta: Hymenoptera: Encyrtidae). Zoological Studies 44(3): 347-360 